\title{
Parâmetros químicos e biológicos indicadores de qualidade de solo sob cultivo de braquiárias e soja no oeste paulista
}

\author{
Leila Elvira Pavanelli ${ }^{1}$, Fabio Fernando de Araújo ${ }^{2}$
}

\begin{abstract}
Na avaliação da qualidade de solo têm-se buscado diferentes parâmetros químicos e biológicos que possam ser utilizados como indicadores. Nesse sentido, este trabalho avaliou e correlacionou parâmetros biológicos e de fertilidade em solos provenientes de dois sistemas de cultivo empregados na região Oeste de São Paulo, buscando selecionar indicadores químicos e biológicos de qualidade. Amostras de solos (latossolos e argissolos) de áreas sob cultivo de pastagens (braquiárias) e de cultivo de soja foram coletadas em sete municípios da região, em 2006, sendo avaliadas quanto à fertilidade, nodulação de soja, atividade das enzimas desidrogenase e fosfatase e densidade populacional de bactérias termorresistentes. A maioria dos solos avaliados apresentou baixa fertilidade. Os resultados encontrados demonstraram que a nodulação ocorreu em todos os solos avaliados, porém foi maior nos locais com predominância de Argissolos. O crescimento de soja foi satisfatório em todos os locais. O manejo do solo sob soja não teve efeito significativo sobre os indicadores biológicos avaliados, mas em alguns locais houve melhoria do padrão de fertilidade. A atividade da enzima desidrogenase apresentou correlação positiva com a maioria dos indicadores de fertilidade avaliados, demonstrando que essa enzima é um bom indicador de qualidade para a avaliação desses solos.
\end{abstract}

Palavras-chave: Fertilidade do solo, fosfatase, desidrogenase, nodulação, qualidade de solo.

\section{RESUMO}

\section{Chemical and biological parameters as quality indicators of soil under pasture and soybean in western São Paulo}

Biological and chemical parameters have been used as indicators in soil quality evaluation. This work aimed to analyze and correlate biological and fertility parameters in soils from two cropping systems in western São Paulo. Samples from soils under pasture and soybean were collected in seven cities of the region, in 2006, to evaluated fertility, soybean nodulation, activity of dehydrogenase and phosphatase enzymes, and concentration of thermoresistant bacteria. Most evaluated sites showed low soil fertility. Nodulation occurred in all evaluated soils, however it was higher in localities with predominance of claysoils. Soybean growth was satisfactory in all localities. Soli management under soybean did not contributed for significant increments in the evaluated biological indicators, but some sites showed increase in soil fertility. Dehidrogenase activity showed positive and closed correlation with most fertility parameters and may be a good biological indicator of soil fertility.

Key words: Phosphatase, dehydrogenase, nodulation, soil quality. 


\section{INTRODUÇÃO}

A microbiota do solo é a principal responsável pela decomposição da matéria orgânica, pela ciclagem de nutrientes e pelo fluxo de energia dentro do solo, exercendo influência tanto na transformação da matéria orgânica quanto na estocagem de carbono e nutrientes minerais (Machado et al., 1992; Matsuoka, et al., 2003). A biomassa microbiana é a fração viva da matéria orgânica do solo e contém de 1 a $4 \%$ de $\mathrm{C}$ e de 3 a $5 \%$ de $\mathrm{N}$ e representa um reservatório de nutrientes para as plantas. É bem conhecido que o processo de decomposição da matéria orgânica promove a sustentabilidade biológica e a produtividade nos ecossistemas (Peres et al., 2005).

Além da relação C:N e de outras características inerentes à matéria orgânica, a atividade microbiana depende de condições ambientais como: aeração, $\mathrm{pH}$, temperatura, umidade e cobertura vegetal e dos diferentes sistemas de produção utilizados. A influência dessas variáveis sobre a comunidade e a atividade microbiana pode auxiliar na recomendação de práticas culturais que minimizem a competição por nutrientes pelos microrganismos em detrimento das plantas cultivadas ou que aumentem a eficiência da absorção de nutrientes pelas plantas, resultante da mineralização da matéria orgânica do solo (Zilli et al., 2003; Peres et al., 2005). As determinações da biomassa microbiana não fornecem indicações sobre os níveis de atividade das populações microbianas do solo, sendo importante também avaliar parâmetros que indiquem a atividade microbiana, como atividade enzimática, para verificar o estado metabólico das comunidades de microrganismos do solo (Passianoto et al., 2000; Matsuoka et al., 2003). A determinação da atividade enzimática no solo é uma forma de avaliar também a atividade microbiana, indicando mudanças ocorridas na microbiota do solo sem, entretanto, relacioná-las a algum grupo específico de organismos (Andrade \& Silveira, 2004).

Com a expansão da cultura da soja no Brasil, nos últimos anos algumas propriedades da região Oeste do Estado de São Paulo foram arrendadas para o plantio dessa cultura. A rotação de cultura, efetuada nessas áreas, proporciona mudanças nas propriedades químicas e biológicas do solo. Isso ocorre devido, principalmente, às mudanças no sistema de cultivo e à aplicação intensiva de insumos agrícolas. A mudança desse perfil agroecológico pode provocar alterações importantes nas propriedades do solo. Além disso, essa mudança pode contribuir para o aumento da fixação biológica do nitrogênio atmosférico efetuada por bactérias simbiontes da soja. A fixação biológica de nitrogênio no solo (100 a 160 kg de $\mathrm{N} \mathrm{ha}^{-1}$ ), após alguns anos de cultivo da soja, tem suprido as necessidades deste nutriente para diferentes gramíneas cultivadas em sucessão a esta leguminosa (Mascarenhas et al., 2002).

Na avaliação da qualidade do solo devem ser empregados parâmetros indicadores de qualidades física, química e biológica e de suas interações (Kennedy \& Smith, 1995; Trannin et al., 2007, 2008). Dessa forma, cada vez mais se faz necessária a identificação e seleção de parâmetros físicos, químicos e biológicos de solo que possam ser empregados como indicadores de mudanças na qualidade do solo em resposta às práticas culturais (Saviozzi et al., 2001; Trannin et al., 2007, 2008).

O objetivo deste trabalho foi avaliar alguns parâmetros químicos e biológicos de solo e o desenvolvimento da soja para identificar e selecionar os indicadores de qualidade mais sensíveis ao manejo, comparando solos sob pastagens e cultivados com soja.

\section{MATERIAL E MÉTODOS}

A área de estudo situa-se na zona fisiográfica denominada de Pontal do Paranapanema, pertencente à Unidade de Gerenciamento de Recursos Hídricos Pontal do Paranapanema (UGRHI - 22), com 11.838 km², localizada no Oeste do Estado de São Paulo e formada por 26 municípios. Nessa região, foram selecionados, no ano de 2006, sete municípios representativos das características edafoclimáticas e geográficas para a amostragem de solos. Os municípios escolhidos e respectivas classificações dos solos (EMBRAPA, 1999) estão descritos na Tabela 1. A avaliação dos atributos de fertilidade do solo (pH, alumínio, matéria orgânica, cálcio, magnésio, potássio, fósforo, enxofre, CTC e saturação de bases) foi realizada de acordo com a metodologia descrita por Raij \& Quaggio (1983). Nesses municípios foram escolhidas duas áreas para a amostragem de solo, uma cultivada com soja e outra sob cultivo de braquiárias, ambas com o mínimo de três anos em cada sistema de cultivo.

Em cada área, sob diferente sistema de manejo, foram coletadas amostras compostas de solo a partir de uma subamostragem em oito pontos, na profundidade $0-20 \mathrm{~cm}$, dentro de um hectare, representativo de cada manejo. As subamostras foram coletadas com auxílio de uma pá, com abertura de uma minitrincheira com dimensão 30 x 30 x 20 $\mathrm{cm}$. Esse procedimento foi adotado devido à necessidade de se coletar um maior volume de solo em cada amostragem, o que seria muito trabalhoso com o uso de trado convencional. A profundidade de coleta de $0-20 \mathrm{~cm}$ foi escolhida por representar a camada do solo com mais atividade biológica nele (Moreira \& Siqueira, 2006). As amostras de solo foram homogeneizadas no local de coleta, conduzidas ao laboratório em caixas térmicas com gelo e mantidas sob refrigeração de 7 a $10^{\circ} \mathrm{C}$ até o momento das análises biológicas descritas a seguir. 
Tabela 1. Classificação dos solos amostrados em sete municípios do Oeste paulista

\begin{tabular}{lcc}
\hline Município & Classificação do solo & Classe textural \\
\hline Taciba & Argissolo Vermelho-Amarelo & Arenosa \\
Anhumas & Argissolo Vermelho-Amarelo & Arenosa \\
Iepê & Argissolo Vermelho & Arenosa \\
Presidente Venceslau & Argissolo Vermelho & Arenosa \\
Santo Anastácio & Argissolo Amarelo & Arenosa \\
Rancharia & Latossolo Vermelho Amarelo & Arenosa \\
Teodoro Sampaio & Latossolo Vermelho & Arenosa \\
\hline
\end{tabular}

Para a avaliação da comunidade de bactérias termorresistentes, $500 \mathrm{~g}$ de solo de cada local e sistema de cultivo foram distribuídos em bandejas plásticas e secos à sombra por 24 horas sob temperatura ambiente. Após esse período, as amostras foram peneiradas em malha de $2 \mathrm{~mm}$ e, em seguida, de cada uma retiraram-se três alíquotas de solo (10g) para serem diluídas em 100 mL de água estéril, contida em frascos de $250 \mathrm{~mL}$. Esse material foi submetido a um choque térmico de $70{ }^{\circ} \mathrm{C}$ por $10 \mathrm{~min}$, visando selecionar os microrganismos resistentes a esse tratamento, como, o gênero Bacillus (Buchanan \& Gibbons, 1975). Posteriormente, foram efetuadas diluições sucessivas, utilizando-se tubos com $9 \mathrm{~mL}$ de água estéril e plaqueamento em meio de cultura ágar nutritivo (AN), com incubação por 72 horas, em estufa a $28^{\circ} \mathrm{C}$. Após este período, foi determinado o número de unidades formadoras de colônias em placas.

A atividade da enzima desidrogenase foi estimada de acordo com a metodologia descrita por Van Os \& Ginkel (2001). Seis amostras de solo (5g) de cada sistema de manejo foram utilizadas no ensaio, sendo três com adição do reagente e três sem adição (controle). Após o peneiramento, as amostras de solo foram acondicionadas em tubos de ensaio e, em seguida, saturadas com 2 $\mathrm{mL}$ de solução de cloreto de trifeniltetrazólio - TTC (2,3,5) a $1 \%$ em tampão tris $0,1 \mathrm{M}(\mathrm{pH} 7,6)$ e $1 \mathrm{~mL}$ de glicose $(0,1 \%)$. O material foi homogeneizado em agitador tipo Vortex e incubado a $30^{\circ} \mathrm{C}$, por 18 horas. Após incubação, $9 \mathrm{~mL}$ de metanol foi adicionado a cada tubo, o conteúdo foi agitado manualmente e filtrado em filtro tipo Whatman $\mathrm{n}^{\circ} 1$. A intensidade da cor vermelha no filtrado (formação de trifeniltetrazólio formazan-TTF) foi determinada espectrofotometricamente a $485 \mathrm{~nm}$, e o resultado foi calculado para quantidade de TTF formado por grama de solo seco.

Para a análise da atividade da enzima fosfatase foi empregado o método descrito por Tabatabai (1994). Para cada amostra de solo de um sistema de manejo, foram realizadas três análises em subamostras de $1 \mathrm{~g}$ de solo seco e peneirado. Esse método baseou-se na determinação colorimétrica do $p$-nitrofenol (coloração amarela), formado após a adição de substratos incolores (p- nitrofenilfosfato) específicos para a enzima avaliada. A leitura foi realizada em espectrofotômetro a $465 \mathrm{~nm}$, e os resultados foram expressos em $\mu$ g de $p$-nitrofenol formado por grama de solo seco.

Para a avaliação da nodulação da soja por Bradyrhizobium spp., presente na comunidade microbiana natural de cada solo, foi realizado um experimento em casa de vegetação, utilizando-se as amostras de solo coletadas nas duas áreas de cultivo em cada um dos sete municípios. O delineamento utilizado foi o de blocos casualizados, com quatro repetições. Amostras de solo de cada área de cultivo foram acondicionadas em vasos com capacidade de $2 \mathrm{~kg}$. Em cada vaso foram semeadas cinco sementes de soja (BRS 185) e, após a emergência, foram conduzidas apenas duas plantas durante 50 dias, em condições ambiente. Decorrido esse período, as plantas foram colhidas, a parte aérea foi separada das raízes, que foram lavadas em água corrente, e, posteriormente, foram destacados os nódulos para contagem. A parte aérea e o sistema radicular foram pesados após a secagem em estufa de circulação forçada de ar a $65{ }^{\circ} \mathrm{C}$ até a obtenção de peso da massa seca constante.

A análise estatística dos dados obtidos foi realizada utilizando-se o programa SISVAR (Ferreira, 2000), sendo empregado o teste de Tukey (5\%) para comparação das médias.

\section{RESULTADOS E DISCUSSÃO}

Os parâmetros de fertilidade analisados nas amostras de solo, coletadas nos diferentes municípios, como esperado, revelam grande heterogeneidade nos resultados (Tabela 2). A maioria dos solos analisados apresenta-se com deficiência no parâmetro saturação de bases (V\%), abaixo de $60 \%$, o que os qualifica como predominantemente ácidos, com baixa fertilidade.

A partir da avaliação da nodulação, verificou-se que os solos de três municípios (Taciba, Anhumas e Iepê) destacaram-se nesse quesito (Figura 1). Os solos destes municípios foram classificados como argissolos (Tabela 1) e são locais de histórico mais antigo de cultivo de soja na região (informação pessoal). A nodulação encontra- 
Tabela 2. Fertilidade dos solos amostrados em sete municípios do Oeste paulista

\begin{tabular}{|c|c|c|c|c|c|c|c|c|c|c|}
\hline \multirow{2}{*}{ Local } & \multirow{2}{*}{$\begin{array}{c}\mathrm{pH} \\
\mathrm{CaCl}_{2}\end{array}$} & \multirow{2}{*}{$\begin{array}{l}\text { M.O. } \\
\text { g dm}^{-3}\end{array}$} & $\mathbf{H}+\mathbf{A l}$ & $\mathrm{Ca}$ & Mg & $\mathbf{K}$ & \multirow{2}{*}{$\begin{array}{c}P \\
\mathrm{mg} \mathrm{dm}^{-3}\end{array}$} & \multirow{2}{*}{$\begin{array}{c}\mathrm{SO}_{4} \\
\mathrm{mg} \mathrm{dm}^{-3}\end{array}$} & \multirow{2}{*}{$\begin{array}{c}\text { CTC } \\
\mathrm{mmol}_{\mathrm{c}} / \mathrm{dm}^{-3} \\
\end{array}$} & \multirow[t]{2}{*}{ V\% } \\
\hline & & & - & $\operatorname{mol}_{c}$ & & & & & & \\
\hline Taciba - soja & 3.9 & 12 & 45 & 4 & 1 & 2.0 & 50 & 1.3 & 52 & 13 \\
\hline Taciba - braquiária & 5.3 & 19 & 25 & 25 & 19 & 4.8 & 57 & 17.8 & 74 & 66 \\
\hline Anhumas - soja & 5.3 & 10 & 23 & 29 & 6 & 3.4 & 141 & 1.3 & 61 & 63 \\
\hline Anhumas - braquiária & 4.5 & 9 & 25 & 5 & 2 & 1.6 & 4 & 1.3 & 34 & 25 \\
\hline Iepêsoja & 5.7 & 28 & 23 & 38 & 33 & 4.1 & 115 & 5.3 & 98 & 77 \\
\hline Iepê - braquiária & 5.2 & 24 & 27 & 20 & 12 & 6.0 & 15 & 18.0 & 65 & 59 \\
\hline P. Venceslau - soja & 4.6 & 11 & 27 & 4 & 4 & 1.3 & 3 & 1.3 & 36 & 26 \\
\hline P. Venceslau - braquiária & 4.4 & 11 & 28 & 4 & 3 & 1.1 & 3 & 4.4 & 36 & 22 \\
\hline S. Anastácio - soja & 5.0 & 13 & 21 & 8 & 7 & 4.4 & 5 & 1.3 & 40 & 48 \\
\hline S. Anastácio - braquiária & 4.9 & 26 & 33 & 15 & 9 & 2.5 & 16 & 3.9 & 60 & 44 \\
\hline Rancharia - soja & 5.0 & 7 & 19 & 6 & 4 & 1.2 & 4 & 1.3 & 30 & 38 \\
\hline Rancharia - braquiária & 4.8 & 7 & 22 & 7 & 3 & 0.6 & 3 & 1.3 & 32 & 33 \\
\hline T. Sampaio - soja & 4.3 & 17 & 59 & 5 & 3 & 0.7 & 3 & 3.9 & 68 & 13 \\
\hline T. Sampaio - braquiária & 4.1 & 19 & 24 & 2 & 1 & 0.5 & 3 & 1.7 & 28 & 13 \\
\hline
\end{tabular}

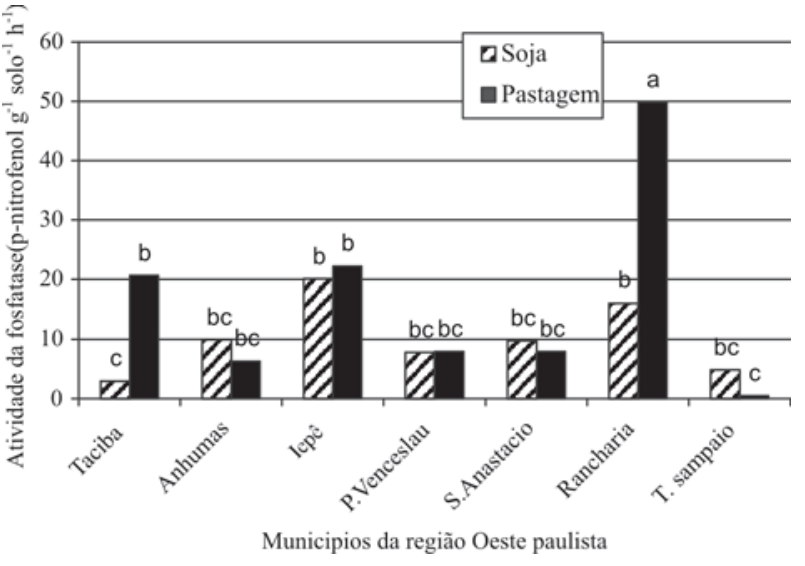

Figura 1. Atividade da fosfatase ( $\mu \mathrm{g}$ de $p$-nitrofenol $\mathrm{g}^{-1}$ solo $^{-1} \mathrm{~h}^{-1}$ ) em amostras de solo provenientes de sete municípios do Oeste paulista em áreas sob pastagens (braquiárias) e soja. Os tratamentos contendo as mesmas letras sobre as barras não diferem estatisticamente pelo teste de Tukey (5\%).

da demonstra que nesses locais já se tem comunidade microbiana de Bradyrhizobium spp. Estabelecida, mesmo nas áreas com cultivo de pastagem. A nodulação encontrada na soja do município de Taciba demonstra boa adaptação de Bradyrhizobium spp em solos ácidos (Tabela 1), pois este solo apresentava $\mathrm{pH}$ muito baixo. Com relação ao comparativo de nodulação em solos sob manejos diferentes observou-se que apenas houve diferença significativa em solo de Anhumas sob cultivo de soja quando comparado com o solo de pastagens (braquiárias).

A produção de massa seca de soja nos solos dos diferentes locais revelou boa adaptação do cultivar para as condições de fertilidade encontrada, independentemente do sistema de manejo na maioria dos locais (Figura 2). O solo de Taciba pastagem apresentou o melhor desempenho nesse parâmetro. As atividades das enzimas avalia-

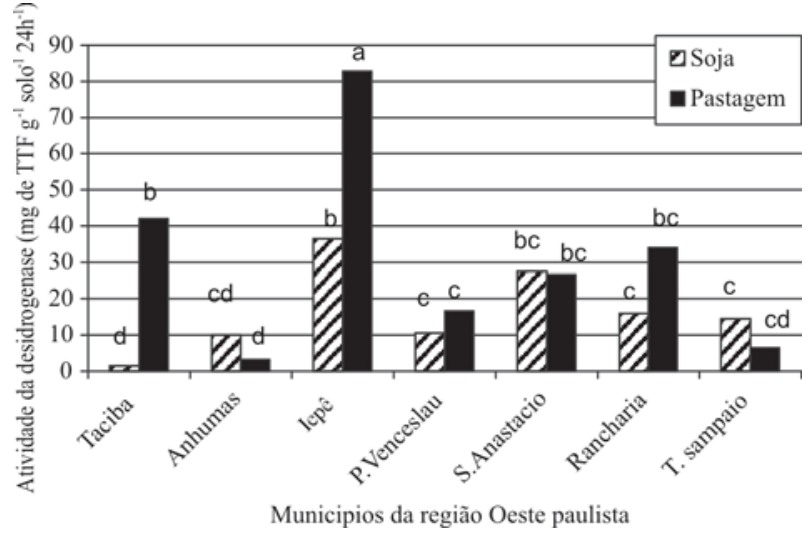

Figura 2. Atividade da desidrogenase (mg de TTF g ${ }^{-1}$ solo $^{-1} 24 \mathrm{~h}^{-1}$ ) em amostras de solo provenientes de sete municípios do Oeste paulista em áreas sob pastagens e soja. Os tratamentos contendo as mesmas letras sobre as barras não diferem estatisticamente pelo teste de Tukey (5\%).

das revelaram que algumas localidades apresentaram valores elevados, porém não coincidentes, em termos de localidade e cultivo, para as duas enzimas avaliadas (Figura 3 e 4). A atividade da enzima desidrogenase foi maior em duas áreas de pastagens, comparando-se com as áreas de soja no mesmo local. Com relação à concentração de bactérias termorresistentes, observou-se que a maioria dos municípios apresentou valores abaixo de 4,0.104 bactérias por g de solo (Figura 5). Apenas o local Anhumas soja mostrou resultados acima de $1,0.10^{6}$ bactérias por $g$ de solo.

A correlação realizada entre as variáveis demonstra que a atividade da enzima desidrogenase apresentou correlações positivas com a maioria dos indicadores de fertilidade avaliados, exceto para o teor de fósforo no solo (Tabela 3). A análise da atividade da fosfatase não apresentou correlações positivas com nenhum parâmetro, su- 


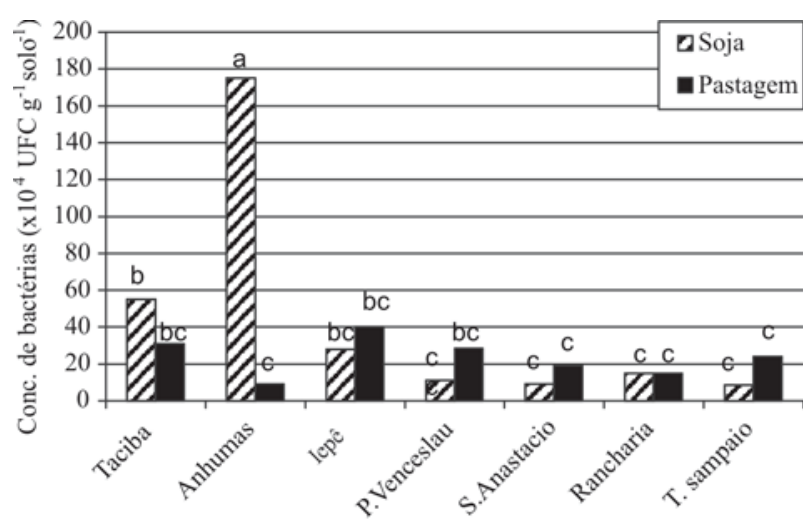

Municípios da região Oeste paulista

Figura 3. Unidades formadoras de colônias de bactérias termorresistentes (ufc g solo-1 ${ }^{-1}$ em amostras de solo provenientes de sete municípios do Oeste paulista em áreas sob pastagens e soja. Os tratamentos contendo as mesmas letras sobre as barras não diferem estatisticamente pelo teste de Tukey (5\%).

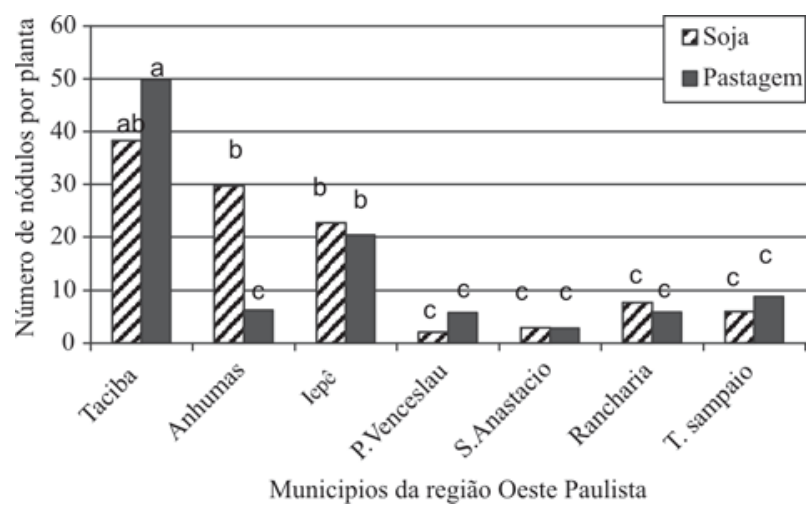

Figura 4. Nodulação em soja (número de nódulos por planta) em amostras de solo provenientes de sete municípios do Oeste paulista em áreas sob pastagens e soja. Os tratamentos contendo as mesmas letras sobre as barras não diferem estatisticamente pelo teste de Tukey (5\%).

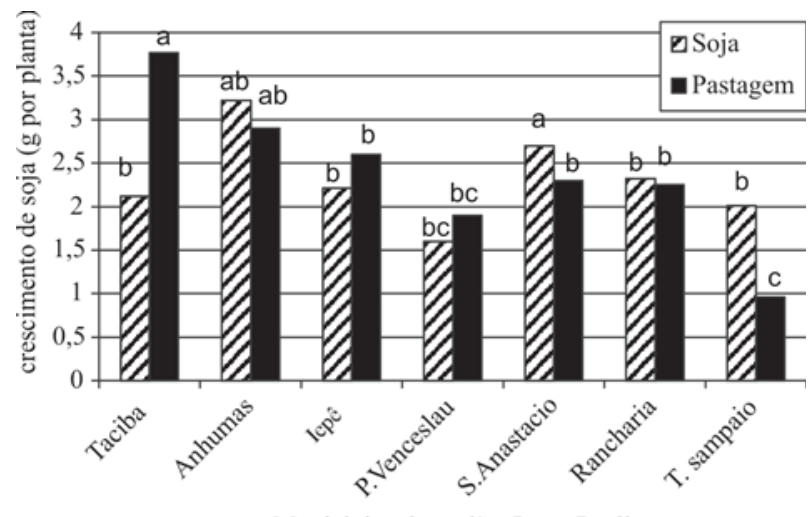

Municipios da região Oeste Paulista

Figura 5. Massa seca da parte aérea e de raiz de soja (g planta ${ }^{-1}$ ) em amostras de solo provenientes de sete municípios do Oeste paulista em áreas sob pastagens e soja. Os tratamentos contendo as mesmas letras sobre as barras não diferem estatisticamente pelo teste de Tukey (5\%). gerindo-se, com isso, que essa enzima possa não ser bom indicador biológico de qualidade de solo. A concentração de bactérias termorresistentes e nodulação de soja apresentaram correlação positiva com a concentração de fósforo solúvel no solo.

O cultivo atual dos solos avaliados não influenciou o desempenho de nodulação e desenvolvimento da soja. A avaliação de nodulação e o crescimento de soja revelaram que a comunidade de Bradyrhizobium presente nos solos apresenta boa adaptação às condições edafoclimáticas da região. A ausência de correlação encontrada entre a nodulação e a maioria dos indicadores de fertilidade confirma esse desempenho.

A presença de Rhizobium tem sido utilizada como indicador de qualidade de solo (Brookes, 1995). Neste trabalho observou-se que a nodulação em soja por Bradyrhizobium apenas apresentou correlação positiva com a concentração de fósforo solúvel no solo. A nodulação de soja ocorreu em solos com baixo padrão de fertilidade, principalmente com característica de acidez. A variabilidade e a adaptação na população de isolados de Bradyrhizobium têm sido relacionadas com vários fatores, incluindo a mutação e recombinação, o que contribui para o estabelecimento destas estirpes no solo (GalliTerasawa et al., 2003). Foi observada a ocorrência de nodulação satisfatória em soja cultivada em solo com pH abaixo de 4,0. (Figura 1). Com isso pode-se sugerir que a nodulação de soja, ou presença de Bradyrhizobium no solo, necessita de mais estudos para posicionamento como indicador de qualidade de solo.

A avaliação da atividade da desidrogenase apresentou correlação positiva com vários índices de fertilidade analisados. A atividade da desidrogenase já foi avaliada, no passado, como índice de fertilidade de solo (Moore \& Russel, 1972). Estes autores concluíram que a enzima não é um bom indicador de fertilidade, porém pode ser útil como indicador de qualidade. A avaliação da desidrogenase tem sido utilizada como indicador biológico, apresentando correlação com outros indicadores de qualidade de solo (Carpenter-Boggs et al., 2000; Quilchano \& Maranon, 2004). A atividade da enzima desidrogenase teve correlação positiva com o pH do solo, V\% e matéria orgânica no solo (Tabela 3). Isso confirma o que foi encontrado por Quilchano \& Maranon (2004), os quais concluíram que além do $\mathrm{pH}$ a atividade da desidrogenase mostra correlação significativa com outros indicadores de fertilidade de solo. Acosta-Martinez \& Tabatabai (2004), avaliando a atividade de várias enzimas em solos corrigidos, concluíram que o $\mathrm{pH}$ do solo é um bom indicador de qualidade do solo e que a atividade da fosfatase correlacionouse negativamente com o pH $(r=-0,69)$. Esse fato indica que a avaliação da atividade da fosfatase como indicador biológico pode não ser útil, reafirmando a ausência de 
Tabela 3. Valores de correlação $\left(\mathrm{R}^{2}\right)$ entre variáveis analisadas

\begin{tabular}{lcccc}
\hline Variáveis & Desidrogenase & Fosfatase & $\begin{array}{c}\text { Bactérias } \\
\text { termorresistentes }\end{array}$ & Nodulação \\
\hline pH do solo & $0,64^{* 1}$ & 0,47 & 0,24 & 0,20 \\
V \% & $0,66^{*}$ & 0,46 & 0,37 & 0,42 \\
Mat. orgânica & $0,56^{*}$ & 0,09 & 0,11 & 0,15 \\
Massa seca de soja & 0,34 & 0,25 & 0,38 & $0,67^{*}$ \\
P (solo) & 0,29 & 0,03 & $0,83^{* *}$ & $0,65^{*}$ \\
\hline
\end{tabular}

${ }^{1}$ Significativo aos níveis de $5 \%\left({ }^{*}\right)$ ou $1 \%(* *)$ de probabilidade.

correlação positiva dessa enzima com outros indicadores encontrados neste trabalho.

A baixa concentração de bactérias termorresistentes nos solos amostrados confirma o encontrado por Araújo et al. (1998), os quais concluíram que os solos da região Oeste paulista estão em processo de degradação. A avaliação de bactérias apresentou correlação positiva apenas com o teor de fósforo solúvel no solo. Em avaliação das doses crescentes de matéria orgânica no solo também não foi encontrado aumento na comunidade dessas bactérias no solo, porém houve aumento na concentração de fungos (Bettiol \& Fernandes, 2004).

Os estudos demonstraram que o manejo de solo sob culturas anuais não contribuiu para incrementos significativos nos indicadores biológicos avaliados. Os solos do Oeste paulista com predomínio do cultivo de gramíneas apresentam potencial para o cultivo da soja, contudo os ganhos na propriedade biológica podem estar dependentes de outros fatores de produção como preparo de solo e utilização de insumos químicos. A nodulação por Bradyrhizobium e o crescimento da soja nos solos avaliados demonstram que os simbiontes estão adaptados às condições edáficas local, sendo que o parâmetro biológico relacionado com a atividade da enzima desidrogenase pode ser útil como indicador de qualidade desses solos, pois apresenta correlação com a maioria dos indicadores de fertilidade do solo avaliados.

\section{CONCLUSÕES}

A mudança de cultivo de pastagens para soja na área de estudo avaliada não proporciona mudanças significativas nos indicadores biológicos avaliados, comparandose os dois tipos de cultivo.

A nodulação em soja, proporcionada por Bradyrhizobium nativo, ocorreu em todas as amostras de solos avaliadas demonstrando que a bactéria consegue se adaptar bem em diferentes condições de solo e cultivos agrícola.

A avaliação da desidrogenase apresenta correlação com os principais parâmetros de fertilidade do solo.

\section{REFERÊNCIAS}

Acosta-Martinez V \& Tabatabai MA (2004) Enzyme activities in a limed agricultural soil. Biology and Fertility of Soils, 31:85-91.

Araújo FF, Rangel Neto J \& Mungo PJ (1998) Avaliação de população de bactérias termoresistentes e sua relação com nutrientes presentes em amostras do solo da região oeste paulista. In: Encontro Anual de Pesquisa e de Iniciação Científica da UNOESTE. Presidente Prudente. Anais, UNOESTE. p. 56-56.

Andrade SAL \& Silveira APD (2004) Biomassa e atividade microbianas do solo sob influência de chumbo e da rizosfera da soja micorrizada. Pesquisa Agropecuária Brasileira, 39:1191-1198.

Bettiol W \& Fernandes SAP (2004) Efeito do lodo de esgoto na comunidade microbiana e atributos químicos do solo. Jaguariúna, Embrapa Meio Ambiente. p.6 (Embrapa Meio Ambiente, comunicado técnico, 24).

Brookes PC (1995) The use of microbial parameters in monitoring soil pollution by heavy metals. Biology and Fertility of Soil, 19:269-279.

Buchanan RE \& Gibbons NG (1975) Bergey's manual of determinative bacteriology. 8.ed. Baltimore-London, The Willians \& Wilkens Co. 1268p.

Carpenter-Boggs L, Kennedy AC \& Reganold JP (2000) Organic and biodynamic management: Effects on soil biology. Soil Science Society American Journal 64:1651-1659.

EMBRAPA (1999) Sistema brasileiro de classificação de solos. Rio de Janeiro, Embrapa Solos. 412p.

Ferreira DF (2000) Análises estatísticas por meio do Sisvar para Windows versão 4.0. In: $4^{\text {a }}$ Reunião anual da região brasileira da sociedade internacional de biometria, São Carlos. Anais, São Carlos: UFSCar. p.255-258.

Galli-Terasawa LV, Glieke-Blanco C \& Hungria M (2003) Diversity of a soybean rhizobial population adapted to cerrados soil. World Journal of Microbiology \& Biotechnology, 19:933-939.

Kennedy AC \& Smith KL (1995) Soil microbial diversity and the sustainability of agricultural soils. Plant and Soil, 170:75-86.

Lupwayi NZ, Rice WA \& Clayton GM (1998) Soil microbial diversity and community structure under wheat as influenced by tillage and crop rotation. Soil Biology and Biochemistry, 30:1733-1741.

Machado AT, Magalhães JR, Magnavaca R \& Silva MR (1992) Determinação et al. da atividade de enzimas envolvidas no metabolismo do nitrogênio em diferentes genótipos de milho. Revista Brasileira de Fisiologia Vegetal, 4:45-47.

Mascarenhas HAA, Tanaka RT \& Wutke EB (2002) Cultivo de cereais e cana-de-açúcar após soja: economia de adubo nitrogenado. O Agronômico, 54:19-20. 
Matsuoka M, Mendes IC \& Loureiro MF (2003) Biomassa microbiana e atividade enzimática em solos sob vegetação nativa e sistemas agrícolas anuais e perenes na região de Primavera do Leste (MT). Revista Brasileira de Ciência do Solo, 27: 425-433.

Moreira FM \& Siqueira JO (2006) Microbiologia e bioquímica do solo. Lavras, Editora UFLA. 729p.

Moore AW \& Russel JS (1972) Factors affecting dehydrogenase activity as na index of soil fertility. Plant and Soil, 37:675-682.

Passianoto CC, Castilhos DD, Castilhos RMV, Lima ACR de \& Lima CLR de (2001) Atividade e biomassa microbiana no solo com a aplicação de dois diferentes lodos de curtume. Revista Brasileira de Agrociência, 7:137-144.

Perez KSS, Ramos MLG \& McManus C (2005) Nitrogênio da biomassa microbiana em solo cultivado com soja, sob diferentes sistemas de manejo, nos cerrados. Pesquisa Agropecuária Brasileira, 40:137-144.

Quilchano C \& Maranon T (2004) Dehydrogenase activity in mediterranean forest soils. Biology and Fertility of Soils, 35:102-107.

Raij B \& Quaggio JA (1983) Método de análise de solo para fins de fertilidade. Campinas, Instituto Agronômico. (Boletim técnico). 81p.
Saviozzi A, Levi-Minzi R, Cardelli R \& Riffaldi R (2001) A comparison of soil quality in adjacent cultivated, forest and native grassland soils. Plant and Soil, 233:251-259.

Tabatabai MA (1994) Soil enzyme. In: Weaver, RW (Org). Methods of soil analysis. Madison, Soil Science Society of America, p.775-833.

Trannin ICB; Siqueira, JO; Moreira, FMS (2008) Atributos químicos e físicos de um solo tratado com biossólido industrial e cultivado com milho. Revista Brasileira de Engenharia Agrícola e Ambiental, 12:223-230.

Trannin ICB; Siqueira, JO; Moreira, FMS (2007) Características biológicas do solo indicadoras de qualidade após dois anos de aplicação de biossólido industrial e cultivo de milho. Revista Brasileira de Ciência do Solo, 31:1173-1184.

Van Os GJ \& Van Ginkel JH (2001) Suppression of Pythium root rot in bulbous Iris in relation to biomass and activity of the soil microflora. Soil Biological \& Biochemistry, 33:1447-1454.

Zilli JE, Rumjanek NG, Xavier GR, Coutinho HLC \& Neves MCP (2003) Diversidade microbiana como indicador de qualidade do solo. Cadernos de Ciência \& Tecnologia, 20:391-411. 